Published in final edited form as:

Environ Res. 2016 November ; 151: 419-427. doi:10.1016/j.envres.2016.08.013.

\title{
Prospective study of ultraviolet radiation exposure and risk of breast cancer in the United States
}

\author{
Rachel D. Zamoiski ${ }^{*}$ D. Michal Freedman, Martha S. Linet, Cari M. Kitahara, Wayne Liu, and \\ Elizabeth K. Cahoon \\ Radiation Epidemiology Branch, Division of Cancer Epidemiology and Genetics, National Cancer \\ Institute, Rockville, MD
}

\section{Abstract}

Although there are few environmental risk factors for breast cancer, some epidemiologic studies found that exposure to solar UV radiation (UVR) may lower risk. Prior epidemiologic studies are limited by narrow ambient UVR ranges and lack lifetime exposure assessment. To address these issues, we studied a cohort with residences representing a wide range of ambient UVR. Using the nationwide U.S. Radiologic Technologists study (USRT), we examined the association between breast cancer risk and UVR based on ambient UVR, time outdoors, a combined variable of ambient UVR and time outdoors (combined UVR), and sun susceptibility factors. Participants reported location of residence and hours spent outdoors during five age periods. Ambient UVR was derived by linking satellite-based annual UVR estimates to self-reported residences. Lifetime values were calculated by averaging these measures accounting for years spent in that location. We examined the risk of breast cancer among 36,725 participants ( $n=716$ cases) from baseline questionnaire completion (2003-2005) through 2012-2013 using Cox proportional hazards models. Breast cancer risk was unrelated to ambient UVR (HR for lifetime $5^{\text {th }}$ vs $1^{\text {st }}$ quintile $=$ $1.22,95 \%$ CI: $0.95-1.56$, p-trend $=0.36$ ), time outdoors (HR for lifetime $5^{\text {th }}$ vs $1^{\text {st }}$ quintile $=0.87$, $95 \%$ confidence interval $(\mathrm{CI}): 0.68-1.10$, $\mathrm{p}$-trend $=0.46$ ), or combined UVR (HR lifetime $5^{\text {th }}$ vs $1^{\text {st }}$ quintile $=0.85,95 \%$ CI: $0.67-1.08$, p-trend $=0.46$ ). Breast cancer risk was not associated with skin complexion, eye or hair color, or sunburn history. This study does not support the hypothesis that UVR exposure lowers breast cancer risk.

\section{Keywords}

Breast cancer; Ultraviolet radiation; Sunlight; Vitamin D; Cancer epidemiology

\footnotetext{
"Corresponding Author: Rachel D. Zamoiski, 9609 Medical Center Drive, Room 7E512, Rockville, MD 20850, Fax: +240.276.7840. rachel.zamoiski@nih.gov.

Publisher's Disclaimer: This is a PDF file of an unedited manuscript that has been accepted for publication. As a service to our customers we are providing this early version of the manuscript. The manuscript will undergo copyediting, typesetting, and review of the resulting proof before it is published in its final citable form. Please note that during the production process errors may be discovered which could affect the content, and all legal disclaimers that apply to the journal pertain.

Conflicts of interest

None to declare.

This study has been approved annually by human subjects review boards at the University of Minnesota (Minneapolis, MN) and the National Cancer Institute (Bethesda, MD).
} 


\section{Introduction}

With the exception of skin cancer, breast cancer is the most common malignancy among women in the United States(Cancer Facts \& Figures 2015, 2015) The strongest and most consistently identified individual risk factors include age, reproduction-related factors (e.g., parity, age at menarche, age at first childbirth, exogenous hormone use), family history of breast cancer, and lifestyle factors such as alcohol consumption, anthropometry, and physical activity(Claus, Risch, \& Thompson, 1991; Kelsey, 1979). Ecological studies have found decreasing breast cancer incidence with increasing proximity to the Equator(Gorham, Garland, \& Garland, 1990; Mandal, St-Hilaire, Kie, \& Derryberry, 2009; Mohr, Garland, Gorham, Grant, \& Garland, 2008). Since latitude is an influential determinant of cutaneous vitamin $\mathrm{D}$ production, these ecologic findings supported the hypothesis that exposure to vitamin D reduces breast cancer risk. However, other epidemiological studies of circulating vitamin $\mathrm{D}$ and breast cancer risk have been inconsistent and preliminary results from a recent large pooled analysis suggest no association with breast cancer risk(Visvanathan et al., 2015).

Several studies have directly examined the relationship between personal UV radiation (UVR) exposure and breast cancer incidence. However, findings have been inconsistent, supporting either a reduced risk(Anderson, Cotterchio, Kirsh, \& Knight, 2011; L. S. Engel et al., 2014; P. Engel, Fagherazzi, Mesrine, Boutron-Ruault, \& Clavel-Chapelon, 2011; John, Schwartz, Dreon, \& Koo, 1999; John, Schwartz, Koo, Wang, \& Ingles, 2007; Yang et al., 2011) or no association (Edvardsen et al., 2011; Fuhrman et al., 2013; Kuper et al., 2009; Lin et al., 2012; Millen et al., 2009). UVR exposure has been estimated in prior studies using a variety of metrics, most commonly either ambient UVR or time outdoors. Many studies reporting an association between UVR and breast cancer have used time outdoors as the metric of UVR exposure,(L. S. Engel et al., 2014; John et al., 1999; Millen et al., 2009; Yang et al., 2011)and some evaluated ambient UVR exposure (Anderson et al., 2011; P. Engel et al., 2011; John et al., 1999; Millen et al., 2009). Overall, few studies investigating relationships between UVR-related factors and risk of breast cancer have been prospective, (Edvardsen et al., 2011; L. S. Engel et al., 2014; P. Engel et al., 2011; John et al., 1999; Kuper et al., 2009; Millen et al., 2009; Yang et al., 2011) and few of these included a wide range of ambient UVR exposures over the course of a lifetime (Table 1) (Anderson et al., 2011; Kuper et al., 2009; Millen et al., 2009; Yang et al., 2011).

The objective of this study is to assess the relationship between ambient UVR, time spent outdoors, sun sensitivity factors, and subsequent risk of first primary breast cancer using data from the United States Radiologic Technologists (USRT) study. This is the first study to prospectively examine multiple UV radiation-related factors in a large nationwide cohort, which has collected information on personal sun sensitivity characteristics, sun exposure over the lifetime, and detailed lifestyle factors in a population from all 50 states exposed to a wide range of ambient UVR. 


\section{Methods}

\subsection{Overview}

The United States Radiologic Technologists (USRT) study is a prospective occupational cohort composed of radiologic technologists who were certified by the American Registry of Radiologic Technologists for at least two years between 1926 and 1982. Detailed descriptions of this cohort have been previously published (Boice, Mandel, Doody, Yoder, \& McGowan, 1992; Doody, Mandel, Lubin, \& Boice, 1998). Briefly, participants were mailed self-administered questionnaires during the following four time periods: 1983-1989, 19941998, 2003-2005, and 2012-2013. Informed consent was obtained to collect medical records. The USRT study has been annually approved by human subjects review boards at the University of Minnesota (Minneapolis, MN) and the National Cancer Institute (Bethesda, MD).

\subsection{Study population}

The study population included female participants who completed the third (2003-2005) and fourth (2012-2013) questionnaires, and reported no history of cancer (other than nonmelanoma skin cancer [NMSC]) at the time of the third questionnaire $(\mathrm{N}=36,725)$. Followup continued from completion of the third questionnaire until the earlier of first primary cancer diagnosis (excluding NMSC) or completion of the fourth questionnaire.

\subsection{Outcome and validation}

Incident breast cancers, defined as first primary malignant breast cancer diagnosis after the third questionnaire, were ascertained from the fourth questionnaire through self-report $(\mathrm{n}=557)$. Medical records to confirm breast cancer diagnoses were obtained for $368(66.1 \%)$ women, of whom 364 (98.9\%) were confirmed. Because the confirmation rate for selfreported breast cancer diagnosis has been high in this study,(Doody et al., 1998) women with non-validated breast cancers $(\mathrm{n}=189)$ were also included. We also included 163 cases of malignant breast cancer that were not self-reported on the questionnaire, but were found upon review of medical records, bringing the total number of breast cancer cases to 716 .

\subsection{UV radiation exposure assessment}

Lifetime residential history, lifetime time spent outdoors, and host characteristics of sun sensitivity were ascertained at the baseline of this study (third questionnaire).

Residential history and time spent outdoors in the summer were used to estimate UVR exposure. Participants reported the city and state where they lived for the longest time during five age periods over their lifetime $(0-12,13-19,20-39,40-64,65+)$. These residential locations were geocoded and linked to the Total Ozone Mapping Spectrometer database, maintained by NASA ("National Aeronatics and Space Administration: Total Ozone Mapping Spectrometer Data Product: Erythemal UV Exposure," 2004). This database provides estimates of daily noon-time erythemal UVR exposures on a $1.25^{\circ}$ longitude by $1^{\circ}$ latitude (approximately $110 \times 110 \mathrm{~km}$ or $69 \times 69$ miles) grid. Satellite-based annual estimates of UVR have varied little since the start of measurements in the late 1970s, (Lean 
et al., 1997) thus, daily noon-time estimates were averaged over years 1978 to 1993 to construct stable estimates. This measure is referred to as ambient UVR.

Participants also reported the typical time spent outside categorically $(0,<1,1-2,3-4,5-6$ hours/day) on summer weekdays and weekends between 9 AM and 3 PM for the same 5 age periods of their lifetime. We assigned continuous values to each category as follows: 0 was assigned 0.1 hour (since it is unlikely that individuals spent zero time outside), < 1 hour was assigned 0.5 hours, 1-2 hours was assigned 1.5 hours, 3-4 hours was assigned 3.5 hours, and 5-6 hours was assigned 5.5 hours. We then generated a weighted average of weekday and weekend hours to represent time spent outdoors on a typical summer day for each period of life and hereafter refer to this measure as time outdoors.

We also combined ambient UVR and time outdoors by generating a set of variables to better reflect the actual UVR exposure at each location for each time period. To this end, for each period of life, we multiplied the ambient UVR value by the daily number of hours outdoors. We designated this variable combined UVR.

For each of the three exposure metrics, average lifetime exposures were calculated by generating a weighted average based on the values for each period of life, accounting for the number of years in each. This was done for all three methods of exposure assessment: ambient UVR, time outdoors, and combined UVR.

Each metric was analyzed as a categorical variable with five categories. We assigned quintiles based on the distribution of the average lifetime variable for each metric, and used those cutpoints for the specific age periods.

We also assessed the following self-reported characteristics related to sun sensitivity: skin complexion, natural hair color at age 20, eye color, reaction of skin to sunlight after 30 minutes and after prolonged sun exposure, history of blistering sunburn, and Celtic or Gaelic ancestry.

\subsection{Lifestyle, reproductive, and family characteristics}

We examined other factors associated with breast cancer as potential confounders, including body-mass index (BMI) $\left(\mathrm{kg} / \mathrm{m}^{2}\right)$, physical activity, alcohol consumption, and family history of breast cancer. Physical activity was measured by asking participants to report separately the number of hours they spent per week engaging in moderate (defined as requiring effort but not exhausting) and strenuous (defined as increasing heart rate or causing perspiration) exercise. We then combined these reported values to generate a physical activity variable that represented total hours of combined moderate and strenuous physical activity per week. Reproductive factors known to be associated with breast cancer, including parity, number of live births, menopausal status, history of hormone replacement therapy (HRT), and age at menarche were also assessed. To examine potential surveillance bias, we also ascertained the frequency of dental exams to represent healthcare utilization.

Most of these characteristics were obtained at baseline, or if not available at baseline, then they were ascertained from one of the earlier questionnaires. The exception was reproductive factors, including number of births, menopausal status, and HRT use, which were surveyed 
in the fourth questionnaire but used to represent status at baseline. All participants who reported their age at menopause to be older than their age at baseline $(\mathrm{n}=8781)$ were considered to be pre-menopausal at baseline, and all women whose age at beginning HRT was older than their age at baseline were also considered not to be using HRT $(n=2157)$ at baseline. In addition, women whose first child was born after baseline were treated as nulliparous at baseline $(n=4)$ in these analyses.

\subsection{Statistical analyses}

To evaluate the relationship between UVR exposure, sun sensitivity factors and first primary breast cancer, Cox proportional hazards regression analyses were used to calculate HRs and 95\% confidence intervals (CIs) with age as the time scale which adjusts for age in all models (Korn, Graubard, \& Midthune, 1997). We evaluated risk of breast cancer in relation to categories of time outdoors $(<1,1-1.9,2-2.9,3-3.9$, and $\geq 4$ hours/day), quintiles of ambient UVR, and quintiles of combined UVR. We evaluated risk associated with exposure at ages 0-12, 13-19, 20-39, 40-64, and 65+ separately, as well as average lifetime exposure, and mutually adjusted for all other age periods (i.e., all five age periods in one model). The values for ambient UVR, which were derived from residential location, include locations such as Alaska, North Dakota, and Maine in the lowest quintile and Hawaii, Florida, and Texas in the highest quintile. Average lifetime ambient UVR represents an average of several locations and therefore the highest and lowest quintiles may include participants living in a variety of locations.

We also examined risk of breast cancer associated with the following sun sensitivity factors: skin complexion (dark, medium, light), natural hair color at age 20 (dark brown or black, light or medium brown, and blonde, red, or reddish-brown), eye color (brown, green or hazel, blue), reaction of skin to sunlight after 30 minutes (no change in skin color, tanned no sunburn, mild sunburn, and severe or painful sunburn) and after prolonged sun exposure (not tanned, lightly tanned, moderately tanned, deeply tanned), history of blistering sunburn (yes/ no), and Celtic or Gaelic ancestry (yes/no).

Multivariable models were adjusted a priori for the following established or suspected breast cancer risk factors("Breast cancer and hormone replacement therapy: collaborative reanalysis of data from 51 epidemiological studies of 52,705 women with breast cancer and 108,411 women without breast cancer. Collaborative Group on Hormonal Factors in Breast Cancer," 1997; Kelsey, Gammon, \& John, 1993; Krieger, Strong, Makosky, \& Weuve, 2003; Magnusson, Colditz, Rosner, Bergstrom, \& Persson, 1998; Peters et al., 2009; Xia et al., 2014): birth cohort (before 1930, 1930-1939-1940-1944-1945-1949-1950-1954-19551961), BMI $\left(<18.5,18.5-25,25-30,>30 \mathrm{~kg} / \mathrm{m}^{2}\right)$, race (white, black, Asian/Pacific Islander, other), ever given birth (yes/no), age at first birth (<20,20-24, 25-29, 30-34, 235$)$, age at menarche (under 11,11-12,13-14, 15 and older), ever taken HRT (yes/no), family history of breast cancer (yes/no), physical activity $(0,1-3,4-7,7-14,15$ and higher hours/week of moderate and vigorous activity combined), menopausal status (pre- or post-menopausal), ever given birth (yes/no), number of times given birth $(0,1-2,3-4,5$ and higher), use of oral contraceptives (ever/never), alcohol consumption, and occupational ionizing radiation exposure to the breast (continuous). (Doody et al., 2006; Sigurdson et al., 2009) We 
examined whether mutual adjustment for UVR exposure and sun sensitivity factors, as well as mutual adjustment for ambient UVR and time outdoors, altered findings. We also conducted likelihood ratio tests to examine whether marital status, smoking history, or education improved model fit. Missing values were coded as a separate category and included as indicator variables in analyses. P-values for trend were based on likelihood ratio tests of time outdoors, ambient UVR, and combined UVR coded 1 thru 5 and treated as continuous in models.

We conducted several sensitivity analyses. Prior studies have found varying effects of UVR and vitamin D in pre- vs. post-menopausal breast cancer (P. Engel et al., 2011) and in individuals with a family history of breast cancer compared to those with no family history (L. S. Engel et al., 2014). We therefore generated a multiplicative interaction term to test for effect modification between each UVR metric and both menopausal status and family history and repeated the analyses including these terms in separate models. We also repeated the analyses after excluding participants with a history of NMSC $(n=3504)$ as they may have different screening patterns or different patterns of exposure. In addition, we generated a squared term for each UVR exposure metric to explore non-linear relationships. All hazard models satisfied the proportionality assumption as tested using Schoenfeld residuals. We considered two-sided p-values to be significant at a $\$ 0.05$. Analyses were conducted using SAS 9.3 (SAS Institute Inc., Cary, NC, USA).

\section{Results}

Characteristics of the overall study population are shown in Table 2, and are stratified by UVR exposure in Table 3. The proportions of cases and non-cases are consistent with known risk factors for breast cancer, including positive family history, less exercise, higher BMI, early age at menarche, never giving birth, and being post-menopausal (Table 2). Participant characteristics varied by ambient UVR more than by time outdoors, although certain characteristics, including smoking, exercise, and menopausal status, varied by time outdoors (Table 3). Participant ages ranged from 43-94 years at entry.

None of the sun sensitivity characteristics were associated with risk of breast cancer (Table 4). Constitutional characteristics, including eye color, hair color, and skin complexion were unrelated to breast cancer risk, as was history of blistering sunburns, skin reaction to both short-term and long-term sun exposure, and Celtic heritage (Table 4). Sun sensitivity was also not an effect modifier of UVR and breast cancer risk (Supplementary Figure 1).

The HR for lifetime ambient UVR exposure for the $5^{\text {th }}$ compared to the $1^{\text {st }}$ quintile was 1.22 (95\% CI: $0.95-1.56$, p-trend $=0.36$ ). Our findings were also null for UVR exposure based on time outdoors (HR for lifetime $5^{\text {th }}$ vs $1^{\text {st }}$ quintile $=0.87$ (95\% CI: $0.68-1.10$, p-trend $=$ 0.46). In addition, we found no association with breast cancer risk by combined UVR (HR for lifetime $5^{\text {th }}$ vs $1^{\text {st }}$ quintile $=0.85(95 \%$ CI: $0.67-1.08$, p-trend=0.46). There were also no associations seen between ambient UVR, time outdoors, or combined UVR and breast cancer risk during any of the age periods (Table 5).

Environ Res. Author manuscript; available in PMC 2017 November 01. 
For each of the three methods of estimating UVR exposure, we also found no effect modification by menopausal status or family history of breast cancer (data not shown). There was also no difference in risk after additional adjustment for dental x-rays (a surrogate for healthcare utilization), nor did risk estimates change after exclusion of participants with NMSC (data not shown). The squared UVR exposure terms were also not significant (data not shown). Mutual adjustment for ambient UVR and time outdoors did not result in any meaningful differences in HRs, and p-trend remained non-significant for all models (data not shown).

\section{Discussion}

In this large nationwide prospective study, we found no evidence that lifetime average time outdoors, lifetime average ambient UV, lifetime average combined UVR, sun sensitivity factors or sunburns were related to breast cancer risk, nor did we find an association between time outdoors, ambient UVR, or combined UVR during any time period throughout life. Results did not differ by menopausal status or by family history of breast cancer.

Other epidemiologic studies have examined the relationship between ambient UVR, based on residential locations (Anderson et al., 2011; P. Engel et al., 2011; Millen et al., 2009) or other metrics,(Edvardsen et al., 2011) and breast cancer risk. All but one(P. Engel et al., 2011) study of ambient UVR exposure have not found an association with breast cancer (Anderson et al., 2011; Edvardsen et al., 2011; Millen et al., 2009).

Study results are mixed on the relationship between risk and time outdoors. A few studies have found inverse associations with personal outdoor exposure (Anderson et al., 2011; L. S. Engel et al., 2014; John et al., 1999; Millen et al., 2009). In a cohort study of farmers' wives in two states Engel et al. found a decreased risk in women who reported spending at least one hour/day outdoors 10 years before enrollment in the study (L. S. Engel et al., 2014). John et al. found occupational time outdoors, but not recreational time outdoors, significantly related to risk in the general population (John et al., 1999). In the Women's Health Initiative Observation Study, Millen et al. found that spending less than 30 minutes outdoors in summer or other seasons was related to a $20 \%$ increased risk compared to spending greater than two hours outdoors (Millen et al., 2009). One difficulty with time outdoors as an indicator of UVR exposure is that it is susceptible to residual confounding by physical activity, which has been inversely related to breast cancer risk (Peters et al., 2009). This may be especially problematic in study populations that are likely active outdoors, such as farmers' wives(L. S. Engel et al., 2014) or outdoor workers (John et al., 1999). The study by Millen et al, in contrast, does not focus on a population in which outdoor activities are more likely to be characterized by physical activity. However, their finding that time outdoors is equally protective against risk regardless of season suggests potential residual confounding by physical activity after adjustment.

In addition, one study found an inverse association with a particular type of outdoor exposure, weeks spent on sunbathing vacations, but only during certain early decades of life (Yang et al., 2011). While our study did not investigate vacation time, we found no association with overall summer time outdoors in childhood, adolescence or early adulthood. 
To our knowledge, only two studies(Kuper et al., 2009; Yang et al., 2011) have assessed sun sensitivity factors in relation to breast cancer risk and both failed to find any consistent pattern of association. Studies that have examined sunburns as a surrogate for sun exposure have also not observed an association with breast cancer risk (Edvardsen et al., 2011; Kuper et al., 2009; Yang et al., 2011). Our results are consistent with these prior studies.

Our study has several strengths. The study population consists of a large, geographically diverse cohort, representing a wide range of UVR exposures and a large number of breast cancer cases. We used multiple UVR metrics including ambient UVR, time outdoors, and combined UVR, and analyzed average lifetime exposures as well as exposure during specific periods of life, in addition to sun sensitivity factors and sunburns, while most prior studies typically focused on either ambient UVR or various indicators of time outdoors and frequency of sun-seeking vacations. Our results were consistent regardless of the exposure metric assessed, and did not change after adjustment for dental x-rays (a surrogate for healthcare utilization) or exclusion of participants with a NMSC diagnosis, who may have undergone more intensive cancer screening or who may have had different patterns of exposure.

UVR exposures were reported prior to the date of incident breast cancer diagnoses, and thus were not subject to recall bias or reverse causation. To our knowledge, this is the only study on UVR and breast cancer risk in which UVR exposure takes into account both time outdoors and ambient UVR and which examines exposure over the lifetime as opposed to just one point in time.

UVR exposure may influence breast cancer risk through the cutaneous production of vitamin D (Colston, Berger, \& Coombes, 1989; Koga, Eisman, \& Sutherland, 1988; Welsh, 2004), although a large pooled analysis of serum $25(\mathrm{OH}) \mathrm{D}$ in 17 prospective cohorts showed no association between 25(OH)D levels and breast cancer risk(Visvanathan et al., 2015). While our findings do not support the hypothesis of a protective role of vitamin $\mathrm{D}$, we cannot rule out an effect of vitamin D since we did not have information on serum vitamin D levels at baseline. We also did not have information on sun protection behaviors, such as clothing choices, sunscreen use, or staying in the shade, all of which can influence cutaneous vitamin D production. Additionally, most cohort members were post-menopausal women, many of whom were likely taking calcium + vitamin D supplements, but we did not have information on supplement use. A prior study on a subset of this cohort found that a majority of participants were taking supplements, and that supplementation was a key contributing factor to circulating $25(\mathrm{OH}) \mathrm{D}$ (Freedman et al., 2013). Therefore, in this cohort, UVR exposure may not be associated with vitamin D levels. We lacked information on other sources of UVR exposure, such as the use of tanning beds. Our measures of UVR exposure (time outdoors, ambient UVR, and sun sensitivity factors) relied on self-reported information (residence and time outdoors over the lifetime). While self-reporting of residential histories is likely accurate, there may be difficulties in identifying a single usual residence over a range of years when a person is highly mobile. In addition, there are inherent difficulties in recalling and synthesizing past behavior, such as time outdoors, over periods of time. We also did not collect data on parental socioeconomic status or socioeconomic status at birth. UVR exposure estimates were missing for some individuals. 


\subsection{Conclusions}

In summary, we found no association between any measure of UVR exposure and breast cancer risk. These results do not support a protective role of UVR exposure, either during key age periods in life or across a lifetime, on the development of breast cancer.

\section{Supplementary Material}

Refer to Web version on PubMed Central for supplementary material.

\section{Acknowledgments}

We thank the study participants and Jerry Reid of the American Registry of Radiologic Technologists for their continued support of this study; Diane Kampa and Allison Iwan of the University of Minnesota for study management and data collection; and Jeremy Miller at Information Management Services, Inc. for biomedical computing support. This work was supported by the Intramural Research Program of the Division of Cancer Epidemiology and Genetics, National Cancer Institute, National Institutes of Health, US Department of Health and Human Services, Bethesda MD.

Financial support

This work was supported by the Intramural Research Program of the Division of Cancer Epidemiology and Genetics, National Cancer Institute, National Institutes of Health, US Department of Health and Human Services, Bethesda MD.

\section{References}

Anderson LN, Cotterchio M, Kirsh VA, Knight JA. Ultraviolet sunlight exposure during adolescence and adulthood and breast cancer risk: a population-based case-control study among Ontario women. Am J Epidemiol. 2011; 174(3):293-304. DOI: 10.1093/aje/kwr091 [PubMed: 21659351]

Boice JD Jr, Mandel JS, Doody MM, Yoder RC, McGowan R. A health survey of radiologic technologists. Cancer. 1992; 69(2):586-598. Retrieved from http://www.ncbi.nlm.nih.gov/pubmed/ 1728391. [PubMed: 1728391]

Breast cancer and hormone replacement therapy: collaborative reanalysis of data from 51 epidemiological studies of 52,705 women with breast cancer and 108,411 women without breast cancer. Collaborative Group on Hormonal Factors in Breast Cancer. Lancet. 1997; 350(9084):10471059. Retrieved from http://www.ncbi.nlm.nih.gov/pubmed/10213546. [PubMed: 10213546]

Cancer Facts \& Figures 2015. 2015. Retrieved from http://www.cancer.org/acs/groups/content/ @ editorial/documents/document/acspc-044552.pdf

Claus EB, Risch N, Thompson WD. Genetic analysis of breast cancer in the cancer and steroid hormone study. Am J Hum Genet. 1991; 48(2):232-242. Retrieved from http:// www.ncbi.nlm.nih.gov/pubmed/1990835. [PubMed: 1990835]

Colston KW, Berger U, Coombes RC. Possible role for vitamin D in controlling breast cancer cell proliferation. Lancet. 1989; 1(8631):188-191. Retrieved from http://www.ncbi.nlm.nih.gov/ pubmed/2563099. [PubMed: 2563099]

Doody MM, Freedman DM, Alexander BH, Hauptmann M, Miller JS, Rao RS, Linet MS. Breast cancer incidence in U.S. radiologic technologists. Cancer. 2006; 106(12):2707-2715. DOI: 10.1002/ cncr.21876 [PubMed: 16639729]

Doody MM, Mandel JS, Lubin JH, Boice JD Jr. Mortality among United States radiologic technologists, 1926-90. Cancer Causes Control. 1998; 9(1):67-75. Retrieved from http:// www.ncbi.nlm.nih.gov/pubmed/9486465. [PubMed: 9486465]

Edvardsen K, Veierod MB, Brustad M, Braaten T, Engelsen O, Lund E. Vitamin D-effective solar UV radiation, dietary vitamin $\mathrm{D}$ and breast cancer risk. Int J Cancer. 2011; 128(6):1425-1433. DOI: 10.1002/ijc.25463 [PubMed: 20473950] 
Engel LS, Satagopan J, Sima CS, Orlow I, Mujumdar U, Coble J, Alavanja MC. Sun exposure, vitamin D receptor genetic variants, and risk of breast cancer in the Agricultural Health Study. Environ Health Perspect. 2014; 122(2):165-171. DOI: 10.1289/ehp.1206274 [PubMed: 24252436]

Engel P, Fagherazzi G, Mesrine S, Boutron-Ruault MC, Clavel-Chapelon F. Joint effects of dietary vitamin D and sun exposure on breast cancer risk: results from the French E3N cohort. Cancer Epidemiol Biomarkers Prev. 2011; 20(1):187-198. DOI: 10.1158/1055-9965.EPI-10-1039 [PubMed: 21127286]

Freedman DM, Cahoon EK, Rajaraman P, Major JM, Doody MM, Alexander BH, Linet MS. Sunlight and other determinants of circulating 25-hydroxyvitamin D levels in black and white participants in a nationwide U.S. study. Am J Epidemiol. 2013; 177(2):180-192. DOI: 10.1093/aje/kws223 [PubMed: 23292956]

Fuhrman BJ, Freedman DM, Bhatti P, Doody MM, Fu YP, Chang SC, Sigurdson AJ. Sunlight, polymorphisms of vitamin D-related genes and risk of breast cancer. Anticancer Res. 2013; 33(2): 543-551. Retrieved from http://www.ncbi.nlm.nih.gov/pubmed/23393347. [PubMed: 23393347]

Gorham ED, Garland FC, Garland CF. Sunlight and breast cancer incidence in the USSR. Int J Epidemiol. 1990; 19(4):820-824. Retrieved from http://www.ncbi.nlm.nih.gov/pubmed/2084008. [PubMed: 2084008]

John EM, Schwartz GG, Dreon DM, Koo J. Vitamin D and breast cancer risk: the NHANES I Epidemiologic follow-up study, 1971-1975 to 1992. National Health and Nutrition Examination Survey. Cancer Epidemiol Biomarkers Prev. 1999; 8(5):399-406. Retrieved from http:// www.ncbi.nlm.nih.gov/pubmed/10350434. [PubMed: 10350434]

John EM, Schwartz GG, Koo J, Wang W, Ingles SA. Sun exposure, vitamin D receptor gene polymorphisms, and breast cancer risk in a multiethnic population. Am J Epidemiol. 2007; 166(12):1409-1419. DOI: 10.1093/aje/kwm259 [PubMed: 17934201]

Kelsey JL. A review of the epidemiology of human breast cancer. Epidemiol Rev. 1979; 1:74-109. Retrieved from http://www.ncbi.nlm.nih.gov/pubmed/398270. [PubMed: 398270]

Kelsey JL, Gammon MD, John EM. Reproductive factors and breast cancer. Epidemiol Rev. 1993; 15(1):36-47. Retrieved from http://www.ncbi.nlm.nih.gov/pubmed/8405211. [PubMed: 8405211]

Koga M, Eisman JA, Sutherland RL. Regulation of epidermal growth factor receptor levels by 1,25dihydroxyvitamin D3 in human breast cancer cells. Cancer Res. 1988; 48(10):2734-2739. Retrieved from http://www.ncbi.nlm.nih.gov/pubmed/2834048. [PubMed: 2834048]

Korn EL, Graubard BI, Midthune D. Time-to-event analysis of longitudinal follow-up of a survey: choice of the time-scale. Am J Epidemiol. 1997; 145(1):72-80. Retrieved from http:// www.ncbi.nlm.nih.gov/pubmed/8982025. [PubMed: 8982025]

Krieger N, Strong EF, Makosky C, Weuve J. Breast cancer, birth cohorts, and Epstein-Barr virus: methodological issues in exploring the "hygiene hypothesis" in relation to breast cancer, Hodgkin's disease, and stomach cancer. Cancer Epidemiol Biomarkers Prev. 2003; 12(5):405-411. Retrieved from http://www.ncbi.nlm.nih.gov/pubmed/12750234. [PubMed: 12750234]

Kuper H, Yang L, Sandin S, Lof M, Adami HO, Weiderpass E. Prospective study of solar exposure, dietary vitamin D intake, and risk of breast cancer among middle-aged women. Cancer Epidemiol Biomarkers Prev. 2009; 18(9):2558-2561. DOI: 10.1158/1055-9965.EPI-09-0449 [PubMed: 19690185]

Lean JL, Rottman GJ, Kyle HL, Woods TN, Hickey JR, Puga LC. Detection and parameterization of variations in solar mid- and near-ultraviolet radiation (200-400 nm). Journal of Geophysical Research-Atmospheres. 1997; 102(D25):29939-29956. DOI: 10.1029/97jd02092

Lin SW, Wheeler DC, Park Y, Cahoon EK, Hollenbeck AR, Freedman DM, Abnet CC. Prospective study of ultraviolet radiation exposure and risk of cancer in the United States. Int J Cancer. 2012; 131(6):E1015-1023. DOI: 10.1002/ijc.27619 [PubMed: 22539073]

Magnusson C, Colditz G, Rosner B, Bergstrom R, Persson I. Association of family history and other risk factors with breast cancer risk (Sweden). Cancer Causes Control. 1998; 9(3):259-267.

Retrieved from http://www.ncbi.nlm.nih.gov/pubmed/9684706. [PubMed: 9684706]

Mandal R, St-Hilaire S, Kie JG, Derryberry D. Spatial trends of breast and prostate cancers in the United States between 2000 and 2005. Int J Health Geogr. 2009; 8:53.doi: 10.1186/1476-072X-8-53 [PubMed: 19785775] 
Millen AE, Pettinger M, Freudenheim JL, Langer RD, Rosenberg CA, Mossavar-Rahmani Y, Wactawski-Wende J. Incident invasive breast cancer, geographic location of residence, and reported average time spent outside. Cancer Epidemiol Biomarkers Prev. 2009; 18(2):495-507. DOI: 10.1158/1055-9965.EPI-08-0652 [PubMed: 19190147]

Mohr SB, Garland CF, Gorham ED, Grant WB, Garland FC. Relationship between low ultraviolet B irradiance and higher breast cancer risk in 107 countries. Breast J. 2008; 14(3):255-260. DOI: 10.1111/j.1524-4741.2008.00571.x [PubMed: 18422861]

National Aeronatics and Space Administration: Total Ozone Mapping Spectrometer Data Product: Erythemal UV Exposure. 2004 from Goddard Space Flight Center.

Peters TM, Schatzkin A, Gierach GL, Moore SC, Lacey JV Jr, Wareham NJ, Leitzmann MF. Physical activity and postmenopausal breast cancer risk in the NIH-AARP diet and health study. Cancer Epidemiol Biomarkers Prev. 2009; 18(1):289-296. DOI: 10.1158/1055-9965.EPI-08-0768 [PubMed: 19124511]

Sigurdson AJ, Bhatti P, Chang SC, Rajaraman P, Doody MM, Bowen L, Struewing JP. Polymorphisms in estrogen biosynthesis and metabolism-related genes, ionizing radiation exposure, and risk of breast cancer among US radiologic technologists. Breast Cancer Res Treat. 2009; 118(1):177-184. DOI: 10.1007/s10549-009-0307-3 [PubMed: 19214745]

Visvanathan K, Mondul A, Zeleniuch-Jacquotte A, Mukhtar TK, Smith-Warner SA, Ziegler RG. Abstract P3-07-01: Circulating vitamin D concentrations and breast cancer risk: A pooled analysis of 17 cohorts. Cancer Research. 2015; 75(9 Supplement):P3-07-01. DOI: 10.1158/1538-7445.sabcs14-p3-07-01

Welsh J. Vitamin D and breast cancer: insights from animal models. Am J Clin Nutr. 2004; 80(6 Suppl):1721S-1724S. Retrieved from http://www.ncbi.nlm.nih.gov/pubmed/15585794. [PubMed: 15585794]

Xia X, Chen W, Li J, Chen X, Rui R, Liu C, Yuan P. Body mass index and risk of breast cancer: a nonlinear dose-response meta-analysis of prospective studies. Sci Rep. 2014; 4:7480.doi: 10.1038/ srep07480 [PubMed: 25504309]

Yang L, Veierod MB, Lof M, Sandin S, Adami HO, Weiderpass E. Prospective study of UV exposure and cancer incidence among Swedish women. Cancer Epidemiol Biomarkers Prev. 2011; 20(7): 1358-1367. DOI: 10.1158/1055-9965.EPI-11-0071 [PubMed: 21551241] 


\section{Highlights}

- $\quad$ Prior studies of UVR and breast cancer are inconsistent and limited

- We assessed UVR exposure across the lifetime and in three ways

- $\quad$ Conducted a prospective analysis of UVR exposure and breast cancer risk

- $\quad$ No association of any UVR exposure metric at any age with breast cancer risk

- $\quad$ Our findings suggest UVR exposure does not reduce risk of breast cancer 


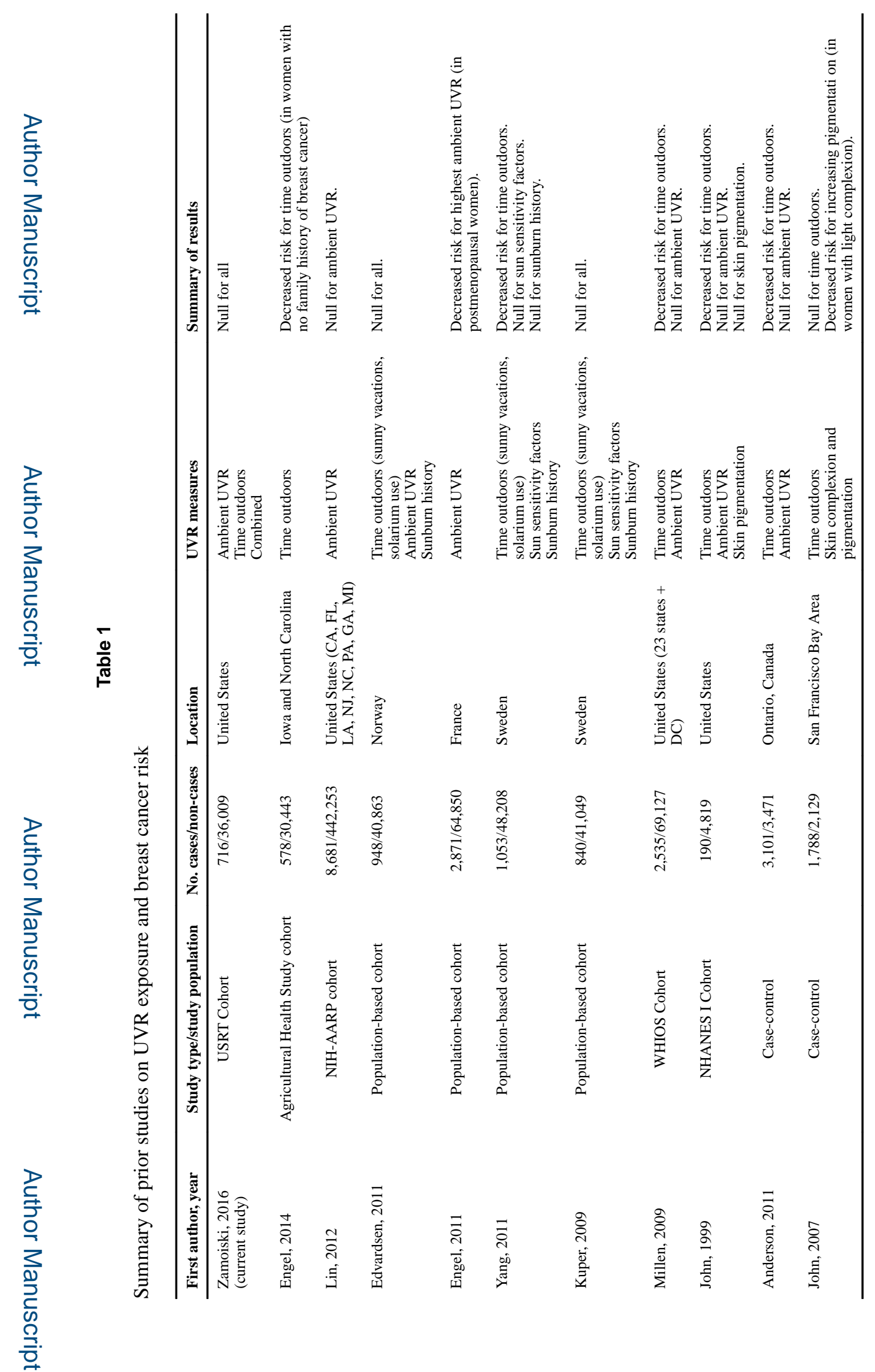

Environ Res. Author manuscript; available in PMC 2017 November 01. 


\section{Table 2}

Demographic, lifestyle, physical, and reproductive characteristics at baseline in breast cancer cases and noncases among 36,725 women in the US Radiologic Technologists Study

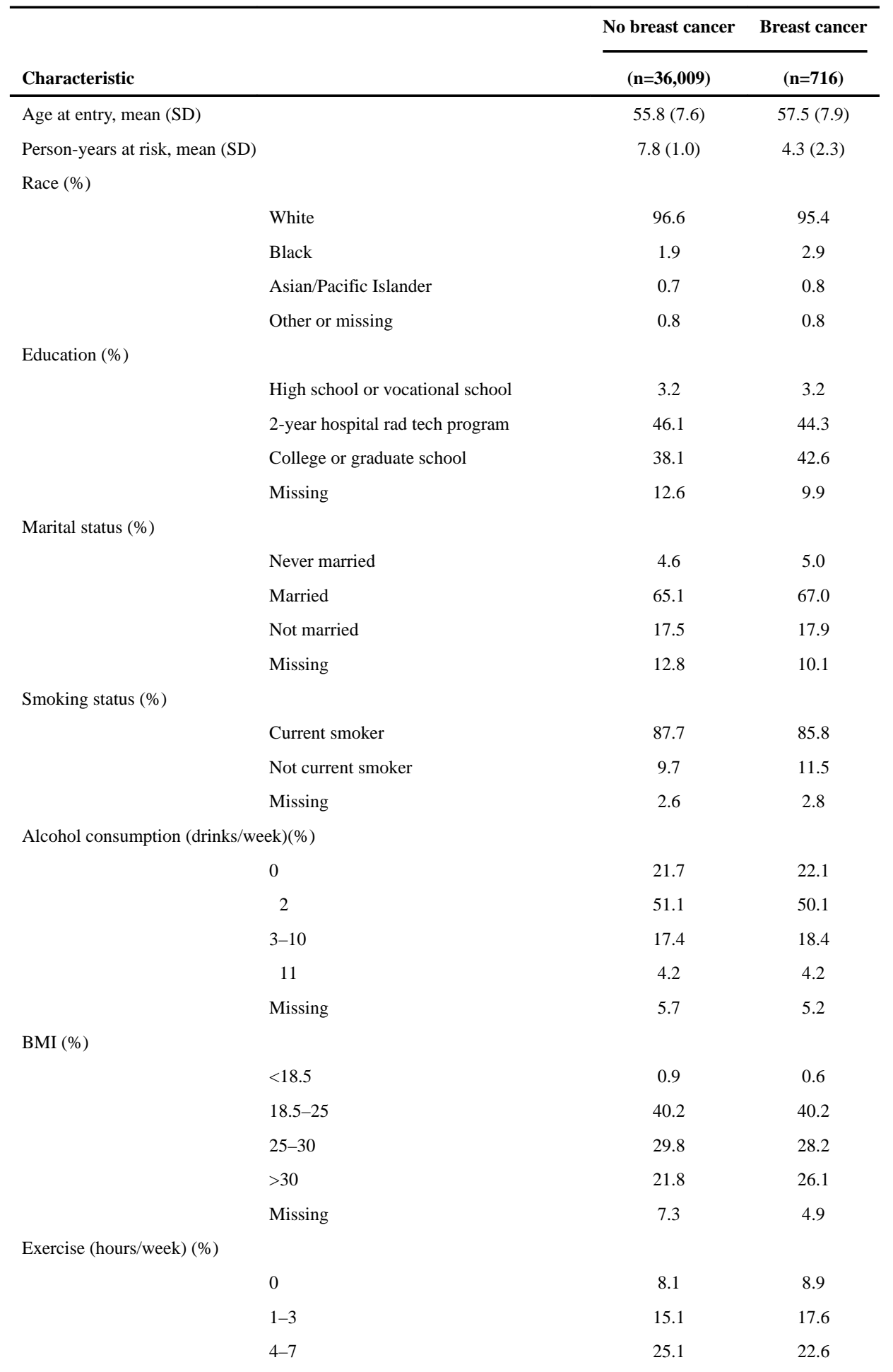




\begin{tabular}{|c|c|c|c|}
\hline \multirow[b]{2}{*}{ Characteristic } & & \multirow{2}{*}{$\frac{\text { No breast cancer }}{(\mathrm{n}=\mathbf{3 6 , 0 0 9 )}}$} & \multirow{2}{*}{$\frac{\text { Breast cancer }}{(n=716)}$} \\
\hline & & & \\
\hline & $8-14$ & 20.0 & 19.0 \\
\hline & $\geq 15$ & 11.4 & 9.2 \\
\hline & Missing & 20.3 & 22.6 \\
\hline \multicolumn{4}{|c|}{ Ever given birth (\%) } \\
\hline & No & 18.6 & 20.1 \\
\hline & Yes & 80.0 & 78.1 \\
\hline & Missing & 1.4 & 1.8 \\
\hline \multicolumn{4}{|c|}{ Number of children (\%) } \\
\hline & 0 & 19.0 & 20.7 \\
\hline & $1-2$ & 52.0 & 52.8 \\
\hline & $3-4$ & 25.2 & 22.6 \\
\hline & $5+$ & 2.7 & 2.9 \\
\hline & Missing & 1.1 & 1.0 \\
\hline \multicolumn{4}{|c|}{ Age at first birth $(\%)$} \\
\hline & Under 20 & 2.6 & 1.8 \\
\hline & $20-24$ & 30.7 & 29.9 \\
\hline & $25-29$ & 31.1 & 30.5 \\
\hline & $30-34$ & 11.5 & 11.2 \\
\hline & 35 and older & 3.9 & 4.9 \\
\hline & Missing & 20.2 & 21.8 \\
\hline
\end{tabular}

Age at menarche $(\%)$

$\begin{array}{lcc}10 \text { and younger } & 6.3 & 7.8 \\ 11-12 & 42.2 & 41.5 \\ 13-14 & 37.3 & 36.6 \\ 15 \text { and older } & 7.3 & 7.8 \\ \text { Missing } & 6.9 & 6.3\end{array}$

Menopausal status (\%)

$\begin{array}{lll}\text { Pre-menopausal } & 27.4 & 22.1\end{array}$

$\begin{array}{lll}\text { Menopausal or post-menopausal } & 69.0 & 74.0\end{array}$

$\begin{array}{lll}\text { Missing } & 3.6 & 3.9\end{array}$

Ever used oral contraceptives (\%)

$\begin{array}{lcc}\text { No } & 21.3 & 26.8 \\ \text { Yes } & 72.5 & 67.7 \\ \text { Missing } & 6.2 & 5.5\end{array}$

Ever used HRT (\%)

$\begin{array}{lcc}\text { No } & 51.3 & 50.1 \\ \text { Yes } & 37.2 & 42.2 \\ \text { Missing } & 11.5 & 7.7\end{array}$

Family history of breast cancer (\%)

$\begin{array}{lll}\text { No } & 50.3 & 41.6 \\ \text { Yes } & 16.6 & 23.2\end{array}$

Environ Res. Author manuscript; available in PMC 2017 November 01. 


\begin{tabular}{lcc}
\hline & No breast cancer & Breast cancer \\
\cline { 2 - 3 } Characteristic & $\mathbf{( n = 3 6 , 0 0 9 )}$ & (n=716) \\
\hline Missing & 33.1 & 35.2 \\
Cumulative occupational ionizing radiation to the breast (mGy), mean (SD) & $23.2(28.4)$ & $26.0(32.5)$ \\
\hline
\end{tabular}




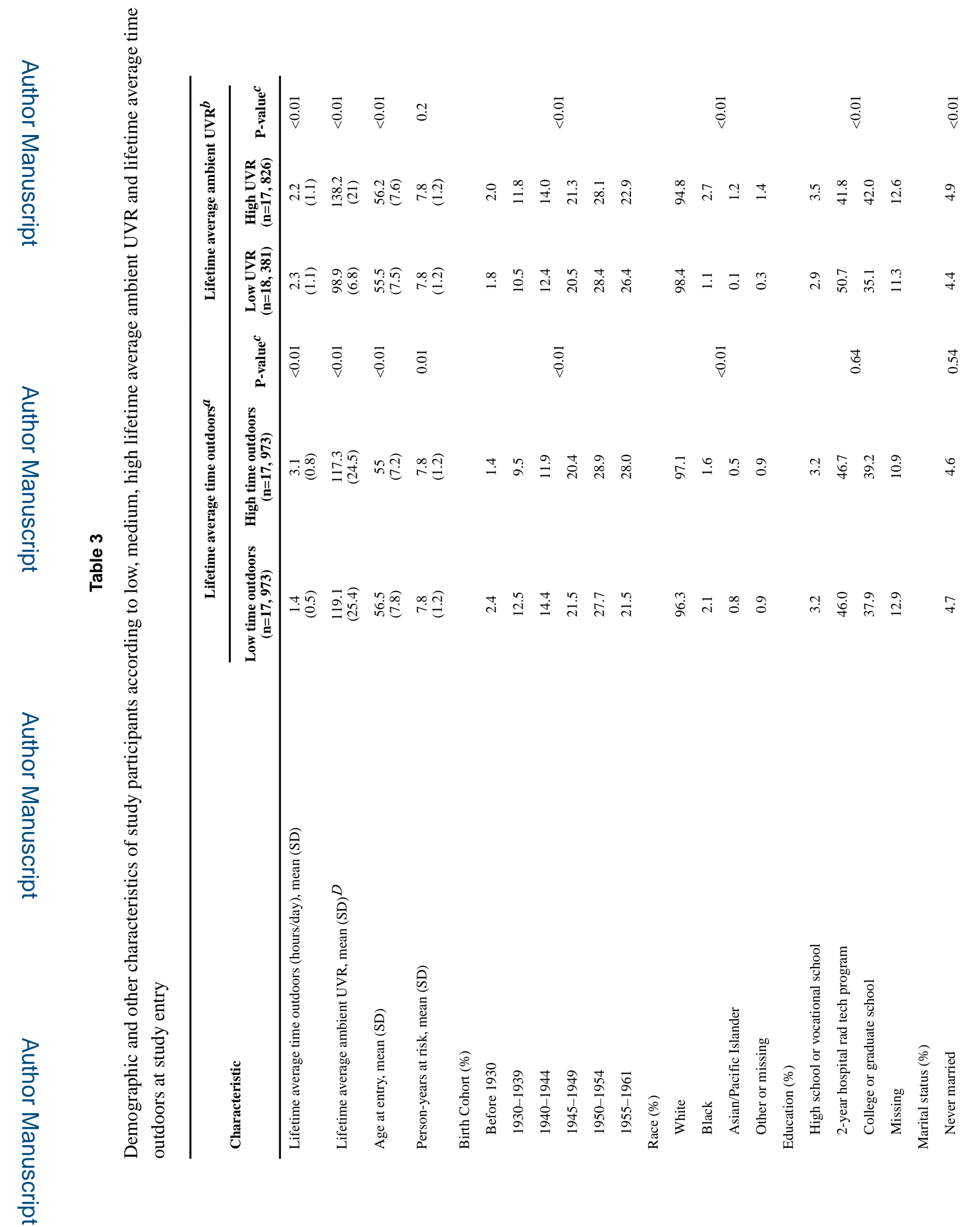

Environ Res. Author manuscript; available in PMC 2017 November 01. 


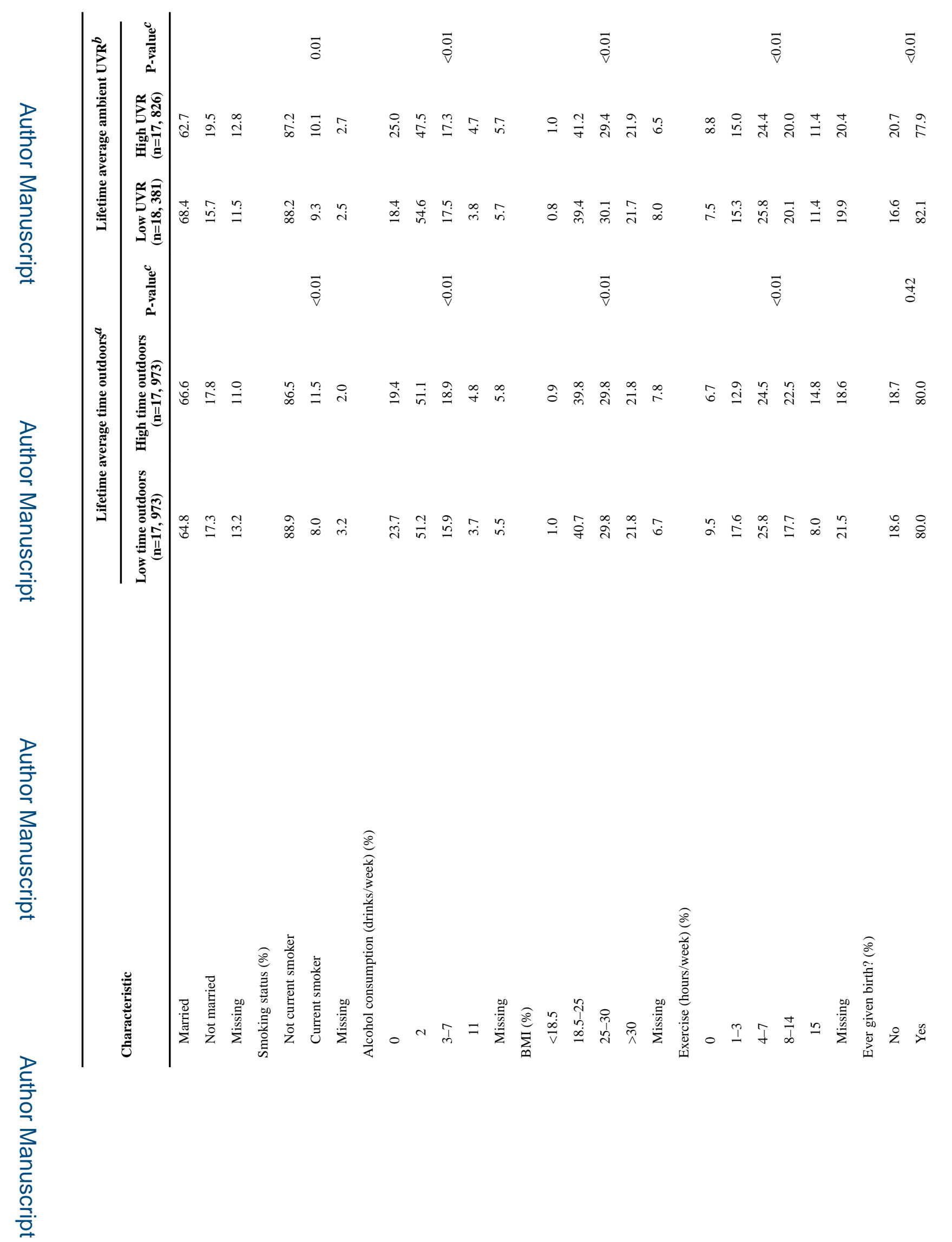

Environ Res. Author manuscript; available in PMC 2017 November 01. 


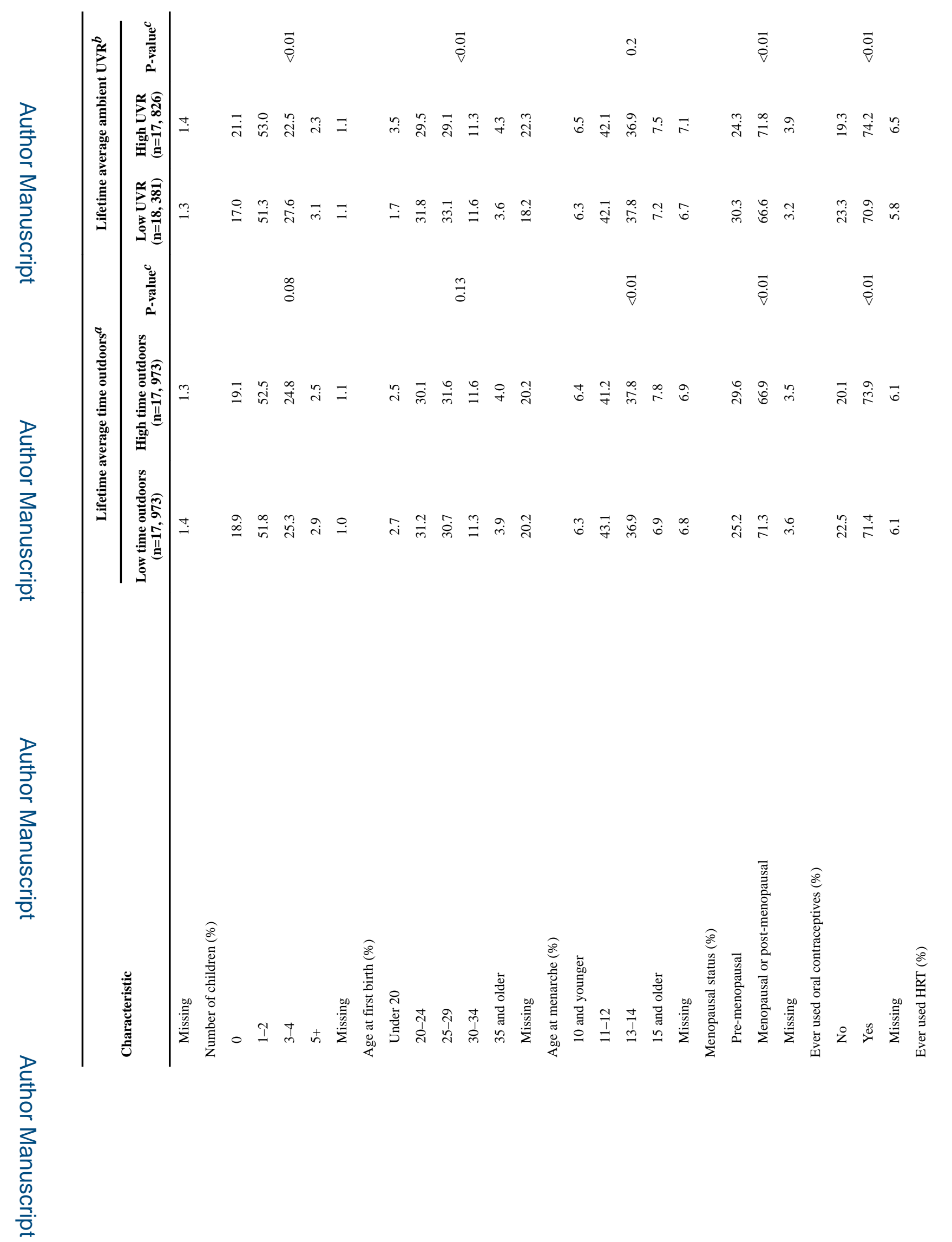
Environ Res. Author manuscript; available in PMC 2017 November 01. 


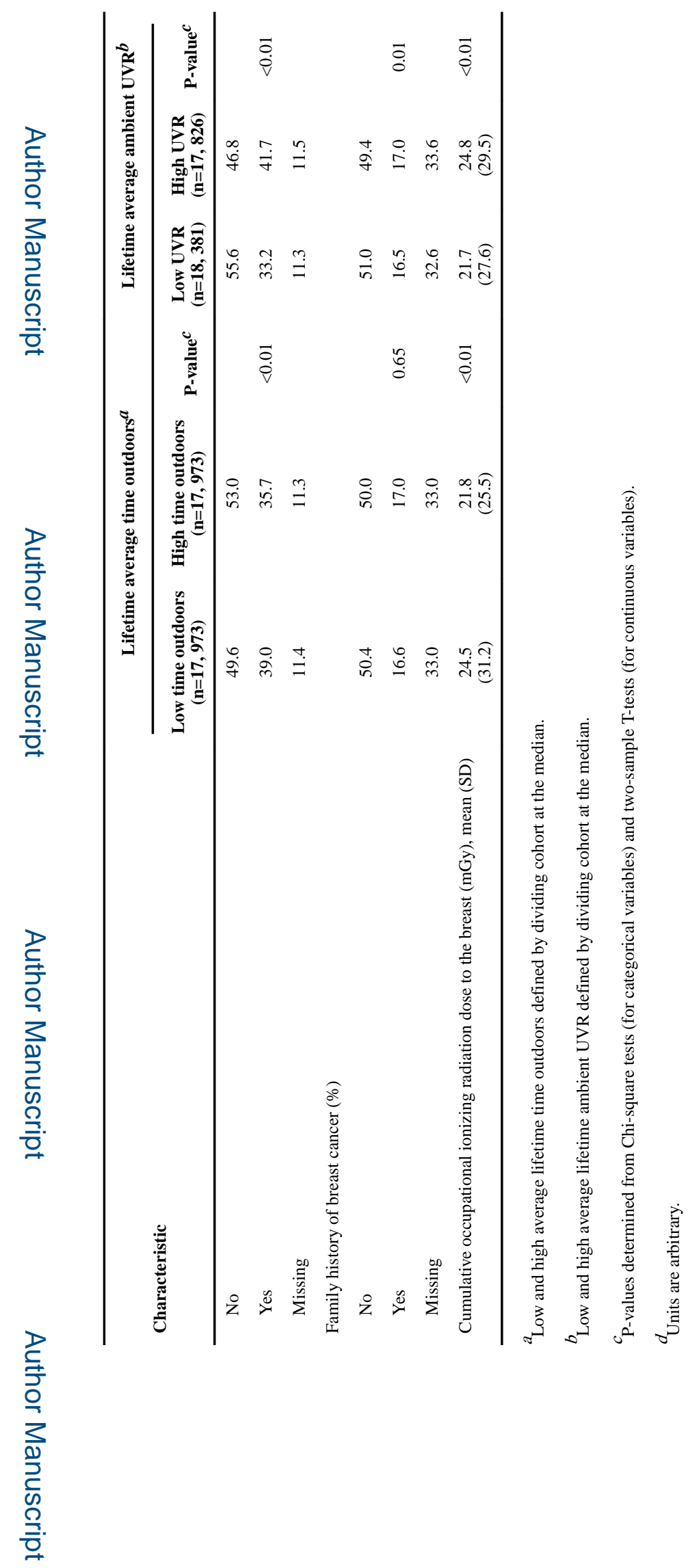

Environ Res. Author manuscript; available in PMC 2017 November 01. 


\section{Table 4}

Risk of breast cancer according to sun sensitivity characteristics among white women in the United States Radiologic Technologists study, 2003-05 through 2012-13 ( $\mathrm{n}=35,456)$

\begin{tabular}{|c|c|c|c|}
\hline Characteristic $^{a}$ & Breast cancer cases, $n$ & Person years & HR $(95 \% \text { CI })^{b}$ \\
\hline \multicolumn{4}{|l|}{ Skin complexion } \\
\hline Dark or medium & 317 & 129912 & ref \\
\hline Light & 300 & 114966 & $1.06(0.91-1.24)$ \\
\hline \multicolumn{4}{|l|}{ Eye color } \\
\hline Brown & 196 & 73342 & ref \\
\hline Green or hazel & 244 & 98696 & $0.93(0.77-1.12)$ \\
\hline Blue & 178 & 72009 & $0.91(0.74-1.12)$ \\
\hline \multicolumn{4}{|l|}{ Natural hair color at age 20} \\
\hline Dark brown or black & 151 & 63923 & ref \\
\hline Light or medium brown & 347 & 139554 & $1.10(0.91-1.33)$ \\
\hline Blonde, red, or reddish-brown & 182 & 70379 & $1.12(0.90-1.39)$ \\
\hline \multicolumn{4}{|l|}{ Skin reaction to 30 minutes of sunlight } \\
\hline Tanned without sunburn or no change in skin color & 69 & 32034 & ref \\
\hline Mild sunburn & 350 & 142002 & $1.19(0.92-1.54)$ \\
\hline Severe or painful sunburn & 262 & 100462 & $1.21(0.93-1.58)$ \\
\hline \multicolumn{4}{|l|}{ Skin reaction to prolonged sunlight } \\
\hline Lightly tanned or not tanned & 181 & 74713 & ref \\
\hline Moderately tanned & 335 & 129429 & $1.11(0.93-1.33)$ \\
\hline Deeply tanned & 159 & 69745 & $1.01(0.82-1.25)$ \\
\hline \multicolumn{4}{|l|}{ Ever had a blistering sunburn } \\
\hline No & 242 & 99568 & ref \\
\hline Yes & 439 & 174945 & $1.05(0.90-1.23)$ \\
\hline \multicolumn{4}{|l|}{ Celtic or Gaelic ancestry } \\
\hline No & 355 & 146590 & ref \\
\hline Yes & 160 & 57112 & $1.07(0.89-1.30)$ \\
\hline
\end{tabular}

${ }^{a}$ Participants with unknown or missing information are not presented.

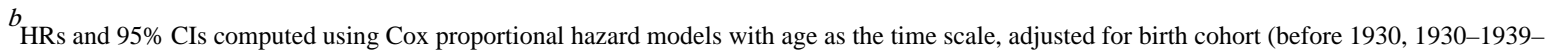
1940-1944-1945-1949-1950-1954-1955-1961), BMI (<18.5, 18.5-25, 25-30, >30 kg/m²), ever given birth (yes/no), age at first birth (<20,2024, 25-29, 30-34, 235), age at menarche (under 11, 11-12, 13-14, 15 and older), ever taken HRT (yes/no) family history of breast cancer (yes/no), exercise ( $0,1-3,4-7,7-14,15$ and higher hours/week), menopausal status (pre- or postmenopausal), number of births (0, 1-2, 3-4, 5 and higher), use of oral contraceptives (ever/never), alcohol consumption $(0,1-2,3-10,11$ and higher drinks/week), and ionizing radiation exposure to the breast (continuous). 


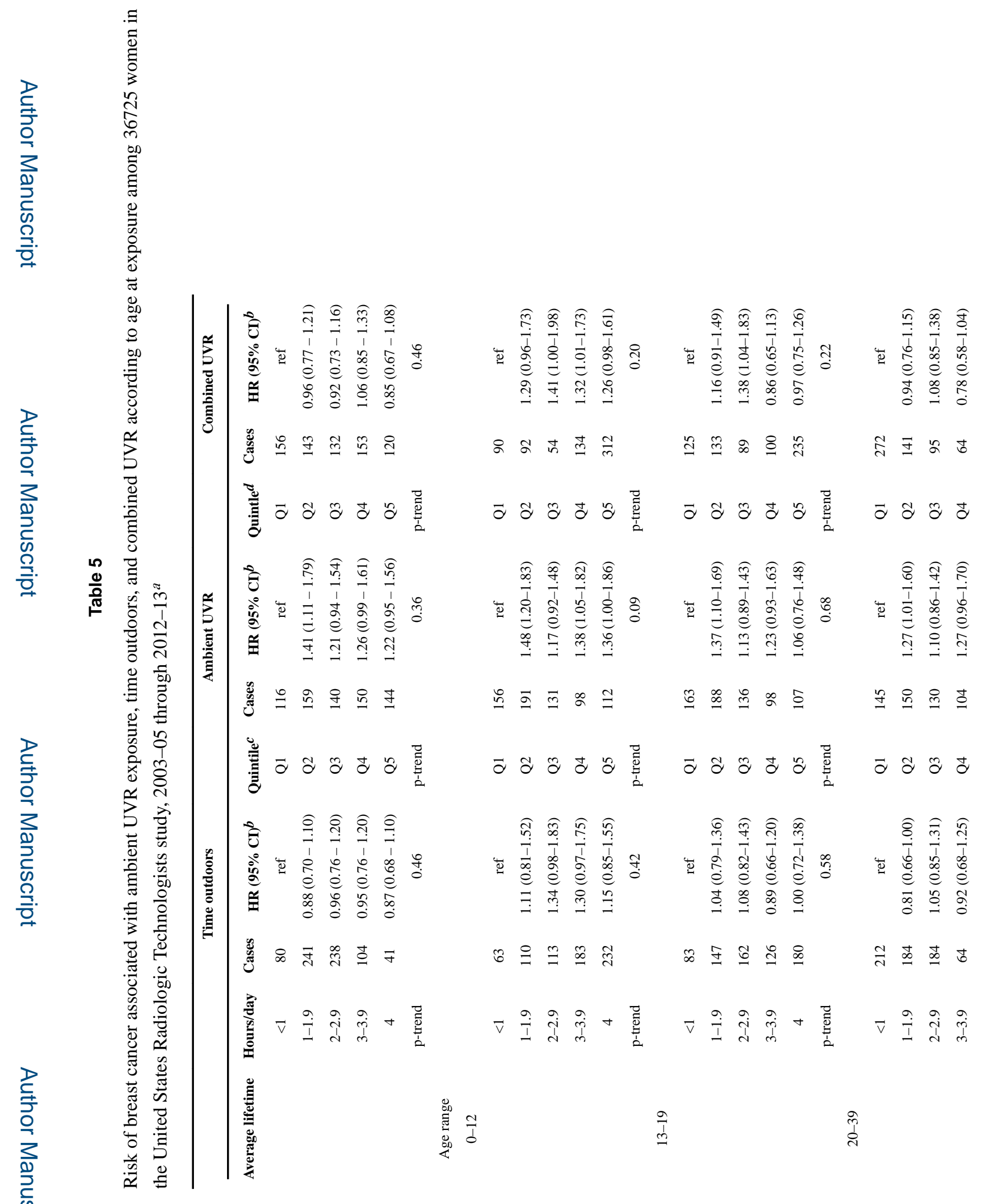




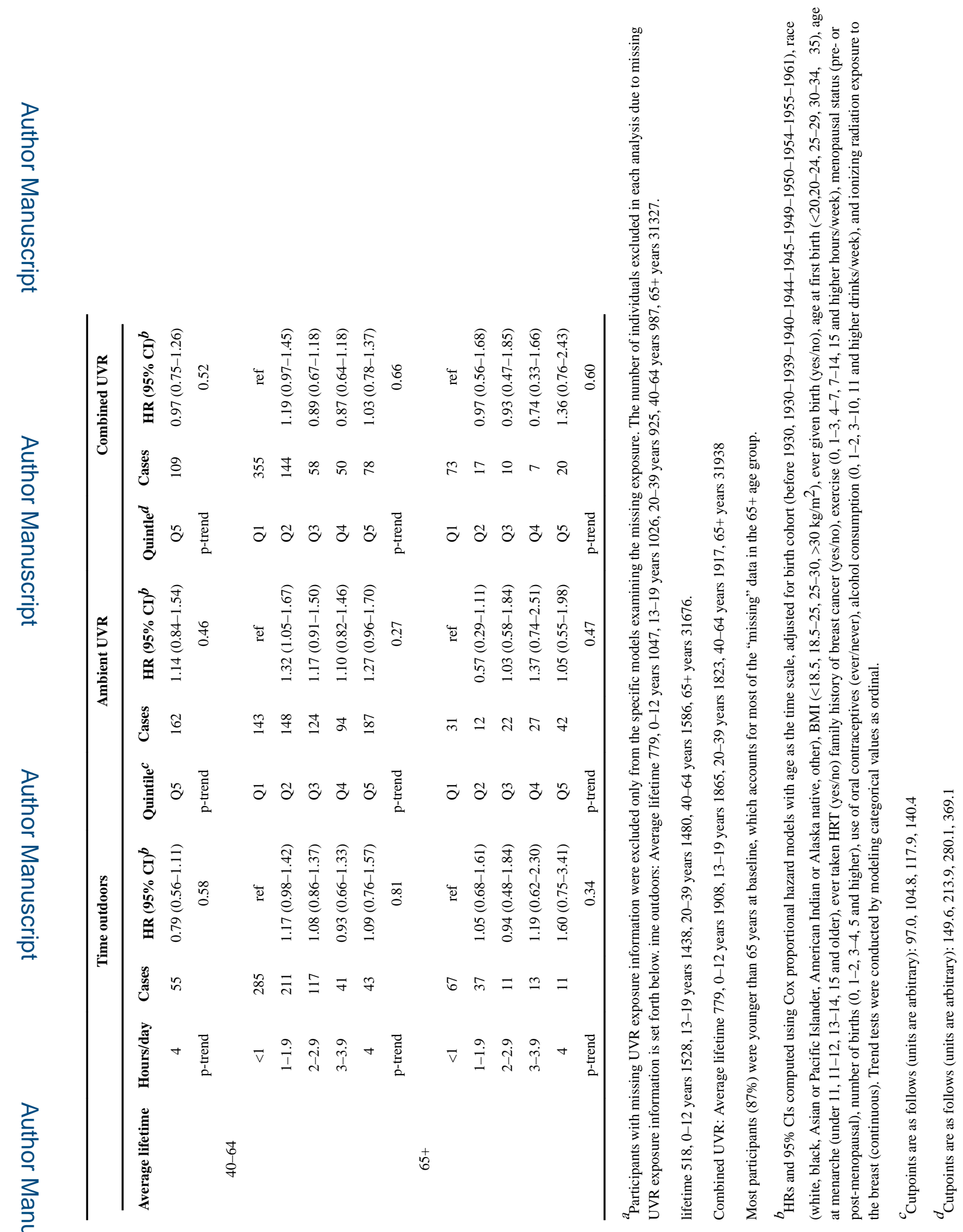

